https://doi.org/10.30910/turkjans.685088

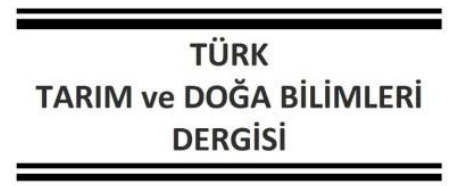

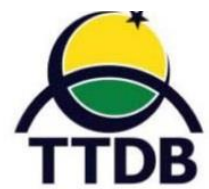

www.dergipark.gov.tr/turkjans

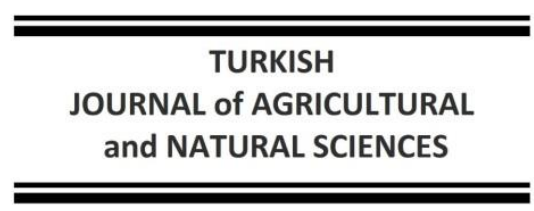

Araştırma Makalesi

\title{
Bingöl ilinde Yaşanan Koloni Kayıpları (Arı Ölümleri), Nedenleri ve Öneriler
}

\author{
Mehmet Ali KUTLU1', Abdurrahman GÜL²
}

Bingöl Üniversitesi Arıcılık Araştırma, Geliştirme ve Uygulama Merkezi 12000 Bingöl, Türkiye

Bingöl Üniversitesi Veteriner Fakültesi Klinik Öncesi Bilimleri.12000 Bingöl, Türkiye

Sorumlu Yazar: kutlular@hotmail.com

Geliş Tarihi: 05.02.2020 Düzeltme Geliş Tarihi: 07.10.2020 Kabul Tarihi: 09.10.2020

\section{Öz}

Bu çalışma, 2018 yılında ülke genelinde olduğu gibi Bingöl ilinde de yaşanan olağan üstü koloni kayıpları ve nedenlerinin tespitine yönelik olarak yapılmıştır. Çalışmanın ana materyalini 2018 yılı Nisan ve Ekim ayları arasında Bingöl Üniversitesi Veteriner Fakültesi Arı Hastalıları Teşhis laboratuvarına bildirilen 28 adet koloni kayıp vakalarının teşhisi, ölümlerin yaşandıkları arılıklar ve çevresinde bulunan diğer arılıkların incelenmesi oluşturmuştur. Hastalık ve zararlıların Bingöl koşullarında aylara göre dağılımı, arıcıların mesleki bilgi ve deneyimlerinin hastalıklarla arasındaki ilişki ve koloni kayıplarının nedenleri araştırılmıştır. Bingöl'de 2018 yılında yaşanan koloni kayıpları \%43 oranında koloni çökmesi bozukluğu (CCD) ki büyük oranda besin yetersizliği, \%25 oranında varroa zararlısı, \%18 oranında Nosema ve \%14 oranında genel yavru çürüklüğü oluşturmuştur.

Anahtar kelimeler: Arı ölümleri, Bingöl, Koloni kayıplar

\section{The Colony Losses in Bingol Province (Bee Deaths), Causes and Suggestions}

\begin{abstract}
This study was carried out in 2018 in order to determine the extraordinary colony losses and causes in Bingöl province as in the whole country. The main material of the study was the diagnosis of 28 colony loss cases and examination of bee yards where deaths happened and other bee yards around which were reflected in Bingöl University Veterinary Faculty Bee Disease Diagnosis laboratory between April and October. The distribution of diseases and pests according to the months in Bingöl conditions, the relationship between the professional knowledge and experiences of beekeepers and the causes of colony losses were investigated. Colony losses occurred in Bingöl in 2018 were $43 \%$ of cases of colony collapse and a large percentage of food deficiencies, $25 \%$ of varroa pests, $18 \%$ of Nosema and $14 \%$ of general foul rot.
\end{abstract}

Key Words: Bee deaths, Bingöl, Colony losses

\section{Giriş}

Arıcılık, bitkisel kaynakları ve arıyı kullanarak, insanın yaratılışından günümüze beslenme ve geleneksel tedavide kullanmaktan vazgeçemediği bal, arı sütü, polen, balmumu, propolis, arı zehri gibi arıcılık ürünleri ile ana arı, oğul gibi canlı materyallerin üretildiği tarımsal bir faaliyettir. Arıların bitki tozlaşmasındaki etkisi de dikkate alındığında arıcılığın tarım sektörü içindeki rolü daha belirgin bir şekilde ortaya çıkmaktadır (Fıratlı ve ark. 2001; Bingöl ve ark. 2014). Ülkemizin dört bir yanında arıcılık yapılmakta olup arı varlığı, bitki örtüsü ve ekolojik yapısı bakımından söz sahibi ülkeler arasında yer almaktadır. Türkiye'de 10.000 'in üzerinde çiçekli bitki türü, bölgeye uyum sağlamış arı ırk ve ekotipleri bulunmaktadır. Bitki türlerinde ve arı popülasyonlarındaki zenginlik, coğrafi bölgelerin iklim ve bitki örtüsü açısından 
farklı ekolojiler göstermesinden kaynaklanmaktadır (Fıratlı ve ark. 2000, Kumova, 2000; Karakaya ve Kızıloğlu 2015). Arılar, doğada tarımsal ürünlerin önemli tozayıcılarıdır (Özbek, 2010, Potts ve ark. 2010, Tüzün ve ark. 2013, Garibaldi ve ark 2013). Arıların bitkisel üretim ve çeşitliliğine katkısı kendi üretimleri olan bal ve ürünlerin ekonomik değerlerinin yaklaşık 15 katı kadardır (Köseoğlu ve ark. 2008). Dünya ballı bitkilerin 3/4‘ ü ülkemizde yetişmektedir. Ülkemiz 8 milyona yakın kovan varlığı bakımından dünyada Çin'den sonra 2. sırada yer almaktadır. Ancak kovan başına düşen bal verimi ise yıllara göre değişi göstermekle birlikte ortalama 13-15 kg civarındadır (Tüik 2018; Söğüt ve ark., 2019a). Bingöl Doğu Anadolu Bölgemizin ballı bitkiler florası bakımından zengin illerinden birisidir. Yapılan çalışmalara göre il genelinde yaklaşık 80 tür ballı bitkiyi barındırmaktadır (Bakoğlu ve ark. 2013). Bingöl'de 2018 yılında 142.234 adet arılı kovanla 1.369,907 ton bal üretimi gerçekleştirilmiştir( Tüik 2018). Kovan başına bal verimi ise ülke ortalamasının bir hayli altında 9,6 kg'dır. Bu çok düşük bir rakamdır. Nedenlerine bakıldığında arıcıların eğitim düzeylerinin yetersizliği, bal arısı hastalık ve parazitleri ile etkin mücadele yapılamaması, yanlış ve tekniğine uygun olmayan yetiştirme metotları, bölge ve gezginci arıcılık koşullarına uygun olmayan arı genotipleri ile çalışılması, damızlık özelliklere sahip genç ve kaliteli ana arı üretimi ve temininde karşılaşılan zorluklar, kış kayıpları, ön plana çıkmaktadır( Kutlu 1998, Kutlu 2015). Dünya genelinde arı sayısında endişe verici bir azalma görülmektedir(Biesmeijer 2006, Grixti ve ark 2009, Whitehorn ve ark 2012). Birçok ülkelerde (Amerika, Çin, Yunanistan ve Avrupa) olduğu gibi (Tüik 2018, Fletceher ve ark. 2003, Rortais ve ark. 2005, vanEngelsdorp ve ark.2008, bacandritsos ve ark 2010 ) son yıllarda ülkemizde de (Giray ve ark 2007, Çakmak ve ark. 2019, Ünal 2010) büyük oranda koloni kayıpları yaşanmaktadır. Bunların nedenlerine bakıldığında evrensel bir kimlik kazanmış olan balarısı zararlısı Varroa jacopsoni ve Varroa destructor en zararlı etken durumundadır (Ünal, 2010). Varroa beslenmesini canlı arı üzerinde açmış olduğu açıklıktan sağlamakta olup kütiküla tabakasında bu açıklıklardan diğer hastalık etmenlerinin de girmesine ortam oluşturmuştur. Dolayısı ile Varroa miktarındaki bu artış kolonideki arıların kütiküla tabakasına zarar vermesi sonucu arıya özgü virüslerin kolonide çoğalmasına neden olmaktadır. Varroa zararlısının kireç ve bazı hastalığa karşı duyarlı olduğunu taşıyıcılığının yanı sıra arılarda stres faktörünün de etkili olduğu belirtmektedir (Kutlu, 1998, Genç ve ark. 2011, Yılmaz, 2009). Nosema apis, antibiyotik kullanımı ve uygun olmayan beslenme şartları veya bunların birlikte ortak etkileri de (vanEngelsdorp ve ark.2008, bacandritsos ve ark 2010 ) önemli nedenleri arasında yer almaktadır. Arıcılıkta tanınan hastalık ve zararlıların yanı sıra tespiti yapılamayan etmeninin ne olduğu belirli olmayan birçok hastalık ve zararlılarla mücadele edilmektedir. Arıcılığımız son yıllarda koloni çöküş hastalığının (CCD) tehdidi altındadır. Koloni çöküş hastalığı (CCD) işçi arıların birden bire ortadan yok olması şeklinde ortaya çıkarak kendini göstermektedir. Tarih boyunca bu tip ortadan kaybolmalar daha önceden de belirtilmiş ise de CCD terimi, ilk defa 2006 yılının sonlarında Kuzey Amerika'da giderek büyüyen ve fazla miktarda olan kayıplar için kullanılmıştır (Kutlu ve ark.2015, Yılmaz, 2009). Albert Einstein “Eğer arılar yeryüzünden kaybolursa insanın sadece 4 yıl ömrü kalır. Arı olmazsa döllenme, bitki, hayvan, insan olmaz" cümlesine bakıldığında arıların ve tozayıcı diğer böceklerin insan yaşamındaki önemini vurgulamaktadır(Köseoğlu ve ark.2008). Son yıllarda doğada tarımsal ürünlerin tozayıcısı (Sandrock ve ark 2014) olan bal arılarının dünya genelinde azalması bilim adamlarının dikkatini bu yöne çekmiş ve uluslararası çalışmalara başlanmıştır (Potts ve ark. 2010, Karahan ve ark, 2016).

Bingöl ilinde özellikle 2018 yılı içerisinde yoğun miktarda koloni kayıpları yaşanmış, bunların nedenlerinin tespitine yönelik olarak bu çalışma yapılmış ve öneriler sunulmuştur.

\section{Materyal ve Metot}

Araştırmanın materyalini 2018 yılı içerisinde Bingöl ilinde arıcılık faaliyetlerinin başladığı Nisan ayı ve faaliyetlerin sonlandırıldığı Ekim ayı arasında Bingöl Üniversitesi Veteriner Fakültesi Arı Hastalıları Teşhis laboratuvarına yansıyan koloni kayıp vakalarının yerinde incelenmesi, laboratuvara gelen hastalıklı arı örnekleri, örneklerin geldikleri arılıklar ve çevresinde bulunan diğer arılıkların ziyareti ile yerinde yapılan tespit çalışmaları oluşturmaktadır. Bu kapsamda konu ile ilgili birimimize $28^{\prime} i$ Bingöl yöresi arıcıları olmak üzere toplamda 37 adet başvuru gerçekleştirilmiştir.

\section{Bulgular ve Tartışma}

Kurumda ve arılıkta teşhisi yapılan hastalıkların oransal dağılımına bakıldığında tablo 1'de görüldüğü gibi büyük oranda koloni çöküş hastalığı ön plana çıkmaktadır. Bunu Varroa zararlısı (varroa destructor) izlemektedir. Paraziter bir zararlı olan Varroa yapılan işletmelerin tümünde görülmüştür. Fakat doğrudan koloni 
kaybına olan zararı \%25 ile ikinci sırada yer almıştır. Üçüncü sırada Nosema hastalığı Nosema apis (Zander) tarafından meydana getirilen, sporla çoğalan, bal arılarının (apis mellifera L) midesindeki epitel hücrelerinde bulunan ve çok geniş yayılma alanı gösteren, bir ergin arı hastalığı ve son sırada bakteriyel bir hastalık olan Amerika ve Avrupa yavru çürüklükleri bulunmaktadır. Söğüt ve ark (2019b) tarafından yapılan çalışmada da işletmelerde en çok oranda (\%86) varroa görüldüğü belirlenmiştir.

Tablo 1. Koloni Kayıplarına Neden Olan Hastalıkların \% dağılımı

\begin{tabular}{lcc}
\hline Hastalıklar & Adet & Oran (\%) \\
\hline Varroa zararııı & 7 & 25 \\
\hline Nosema & 5 & 18 \\
\hline Yavru çürüklüğü & 4 & \\
\hline Koloni çökmesi & 12 & 14 \\
& & 43 \\
\hline
\end{tabular}

Tablo 2'de görüldüğü gibi koloni kaybı yaşayan arıcıların mesleki deneyimlerine bakıldığında \%21 oranında 10 yıl, \%32 11-20 yıl, \%32 oranında 31-30 yıl ve \%1 oranında 31 ve üzeri deneyim sahibi oldukları görülmüştür.

Tablo 2. Koloni Kaybı Yaşayan Arıcıların Mesleki Deneyim \% dağılımı

\begin{tabular}{lcc}
\hline Mesleki Deneyim & Arıcı & Oran (\%) \\
$1-10$ & 6 & 21 \\
$11-20$ & 9 & 32 \\
$21-30$ & 9 & 32 \\
31 ve yukarı & 4 & 14 \\
\hline
\end{tabular}

Tablo 3. Koloni Kaybı Yaşayan Arıcıların Bilgi Düzeyleri \% dağılımı

\begin{tabular}{ccc}
\hline Bilgi Düzeyleri & Arıcı & Oran (\%) \\
Yeterli & 6 & 32 \\
Yetersiz & 19 & 68
\end{tabular}

Tablo 3'e bakıldığında söz konusu 28 kişinin arıcılık bilği birikimleri incelenmiş, bunlardan 3 kişiden yeterli bilgi alınamamıştır. \%32 oranında (9 arıcı) yeterli bilğiye sahip oldukları, \% 68 oranında (19 arıcı) ise özellikle hastalıklar konusunda yetersiz oldukları görülmüştür.

Tablo 4. Bingöl ilindeki Arı Zararlısı ve Hastalıkların Aylara Göre Dağılımı

\begin{tabular}{|c|c|c|c|c|c|c|c|}
\hline Hastalık & Nisan & Mayıs & Haziran & Temmuz & Ağustos & Eylül & Ekim \\
\hline Varroa zararlısı & $x$ & $x$ & $x$ & $x$ & $x$ & $x$ & $x$ \\
\hline $\begin{array}{l}\text { Nosema } \\
\text { hastalığı }\end{array}$ & $x$ & $x$ & $x$ & & & & \\
\hline $\begin{array}{l}\text { Yavru } \\
\text { çürüklüğü }\end{array}$ & $x$ & $x$ & & & & $x$ & $x$ \\
\hline Koloni çökmesi & & & & & $x$ & $x$ & $x$ \\
\hline
\end{tabular}

Tablo 4'de görüldüğü Varroa zararlısı çalışmanın yapıldığı dönem boyunca arılıkların tümünde görülmüş olup Bingöl arıcılarının en önemli sorunlarından biri olmaya devam etmektedir. Nosema ilkbahar aylarında kolonilerde tespit edilmiş olup ana nektar akımımı öncesi haziran başından sonra tespit edilememiştir. Yavru çürüklükleri ilkbahar aylarında yoğun olarak görülmüş sonbahar aylarında ise eser miktarda tespit edilmiştir. Bingöl ilinde koloni çökme hastalığı ilk defa büyük oranda ana nektar akımı sonrası gözlenmiştir. Arı hastalıklarla mücadele belirli bir bilgi birikimi ve deneyimi gerektirmektedir. Van ilinde yapılan bir çalışmada 11-20 yıl arası arıcılık deneyimine sahip olan arıcı sayısı ise 32 kişi (\% 45.07) olarak belirlenmiştir 
(Bingöl ve ark. 2014). Bingöl ilinde yapılan bir çalışmada arıcıların eğitim düzeylerinin yetersizliği, yanlış ve tekniğine uygun olmayan yetiştirme metotları, kış kayıplarını ön plana çıkarttığı belirtilmektedir (Kutlu ve ark. 2015). Bingöl Üniversitesi Veteriner Fakültesi Bal arısı Hastalıkları teşhis laboratuvarı kayıtlarına göre, hastalık vakası ilen gelen arıcıların mesleki deneyimlerine bakıldığında \%78 oranında 11 ve üzeri mesleki deneyime sahip arıcılar olduğu tespit edilmiştir.

Arıcılıkta bilgi üretim etkinliğini ve verimliliği sınırlayan önemli bir etkendir. Çünkü koloni yaşamını ve sağlığını doğrudan ilgilendiren bal arısı hastalık, parazit ve zararlıları arıların sadece sağlığını olumsuz olarak etkilemekle kalmayıp; kolonilerde verimi düşürmekte, hatta önlem alınmadığı takdirde koloni yaşamını sonlandırabilmektedir (Genç ve ark. 2011). Konya da yapılan bir çalışmada eğitim, bilgi ve teknik eleman eksikliğinin hastalıklardaki etkisi \%27 oranında tespit edilmiştir (Karahan ve ark 2016). Sever (2008) Karlıova ilçesinde yaptığı çalışmada ise bilgi eksikliği ve devlet desteğinin yetersizliği yöre insanı arıcılıktan ekonomik bir kazanç sağlayamadığını belirtmektedir. Türkiye'de (Çakmak ve ark 2016) bazı bölgelerde \%80'lere kadar varabilen koloni kayıplarını etkileyen faktörler olarak; varroa, nosema, yavru çürüklüğü, yeni nesil tarım ilaçları olan nikotin türevi neonikotinoidler, ana arı yetersizliği, koloni yönetimi ve uzun mesafeli gezginci arıcılığın neden olduğunu bildirilmiştir. Söz konusu 28 kişinin arıcılık bilği birikimleri incelendiğinde $\% 32$ oranında (9 arıcı) yeterli bilğiye sahip oldukları, \%68 oranında (19 arıı) ise özellikle zararlı ve hastalıklar konusunda eksikliklerinin olduğu tespit edilmiştir. Çalışmada 6 kişi arıcılık deneyimi ile ilğili soruyu yanıtsız bırakmışlardır. Her faaliyet kolunun temelini teşkil eden eğitim ilkesi, arıcılık için de geçerlidir. Görüldüğü gibi arıcılık Bingöl'de yapılan arıcılıkta bilgi yetersizlikleri bulunmaktadır. Bunun doğal sonucu olarak da kolonilerde kış kayıpları fazla olmakta ve koloni başına elde edilen bal verimi düşüklük göstermektedir.

Bingöl genelinde ilkbaharın uzaması nektar akımı süresince beklenmeyen iklim koşulları (günübirlik yağan yağmur ve aşırı sıcak hava ) ana nektar akımı döneminde arı kolonilerinde nektar toplamayı engellediği, kolonilerin ana nektar döneminde güçlü olan arı popülasyonuna rağmen yeterli miktarda nektar temin edememiştir. Genel olarak hasat sonrası arı popülasyonunda tarlacı olarak görev yapan yaşlı işçi arıların büyük bir kısmının yoğun çalışma temposuna bağlı olarak yaşamımı yitirdiği, diğer bir ifade ile 80 bin işçi arı popülasyonuna sahip bir koloninin hasat sonrası 60 bine düşmesi yeterli balın olmadığı halde arıcı tarafından kolonideki tüm balın hasat edilmesi sonucu arıların yeterli düzeyde beslenememesi arı hastalık ve zararlılarının başlamasına temel oluşturmuştur.

Bingöl'de bu durum gözlenmiş olup ana nektar akımı sonrası (25 Temmuz) özellikle güçlü koloniler hızla güç kaybetmiştir. Arı popülasyonundaki bu azalmaya paralel olarak ta arı zararlısı Varroa miktarı artış göstermiş olup arı kolonilerine büyük zararlar vermiştir. Trakya Bölgesi arı hastalıkları ve zararlılarını belirlemeyi amaçlayan bir çalışmada, arıcıların koloni kayıp nedenleri yetersiz bakım ve besleme (\%45.8), hastalık ve zararlılar (\%26.8), kötü iklim koşulları (\%15.9) ve yaşlı ana arı (\%5.1) şeklinde sıralanmıştır (Sıralı ve ark 2005). Kutlu ve ark (2015) tarafından Bingöl ilinde yapılan bir çalışmada, bal arısı hastalık ve parazitleri ile etkin mücadele yapılamaması, yanlış ve tekniğine uygun olmayan yetiştirme metotları, bölge koşullarına uygun olmayan arı genotipleri ile çalışılması, damızlık özelliklere sahip genç ve kaliteli ana arı üretimi ve temininde karşılaşılan zorluklar, kış kayıplarının ön plana çıkarttığını belirtmektedirler (Kutlu ve ark. 2015). Van ilinde (Bingöl ve ark 2014) yapılan bir çalışmada Varroa zararlısının koloni kayıplarındaki etkisinin \%15.71 olduğu bildirilmiştir. Bu çalışmada Varroa zararlısının koloni kayıplarına etkisinin \%25 olduğu tespit edilmiştir.

Yapılan gözlemlerde kovanlarda eser miktarda balın bulunduğu polenin ise olmadığı kovan ve etrafında arı ölülerine rastlanılmadığı bazı kovanlarda ise az sayıda arı ölülerine rastlandığı tespit edilmiştir. Popülasyonun tümüyle kovana terk ederek ortadan kayboldukları arıcılar tarafından ifade edildiği gibi tarafımızdan da gözlenmiştir. Koloni çöküşü diye tabir edilen bu vaka birden fazla türde enfeksiyona yol açan bakteri, parazit, virüs ile olumsuz iklim değişimleri gibi dış etmenlerin etkisiyle oluşmaktadır (Bakonyi ve ark 2002, Yue ve ark 2007).

\section{Sonuç ve Öneriler}

Ana arının yumurtlaması için nektar ve polene gereksinim vardır. Bunlardan birinin yetersizliğinde yavru üretimi oldukça kısıtlıdır veya hiç yoktur. Dolayısıyla koloni gelişimi yavaşlar veya tümüyle durur. Buna karşılık petek gözlerinde ne kadar polen olursa olsun kovanda bal yoksa dışarıdan nektar gelmiyorsa veya kolonilere ek besleme yapılmıyorsa açlıktan ölebildikleri gibi, var olan kısıtlı besinin gelecek generasyona kalabilmesi için kendilerini imha edebilmektedirler (Yücel, 2008). Bingöl'de bu oluşuma benzer bazı kovanların önünde toplu halde genç işçi arı ölümlerine rastlanmıştır. 
Bingöl'de genel olarak yaşanan hastalık diye tabir edilen koloni kayıpların bir kısmı besleme hatalarından kaynaklı koloni çökmesi bozukluğu $(C C D)$ olup, bir kısmını ise arılarda yaygın olarak görülen Varroa zararlısı oluşturmuştur.

1-Arıcılıkta ilk kural güçlü sağıklı ve genç ana arılı koloniler ile çalışılmasıdır. Güçlü koloniler güçlü popülâsyonlar oluşturduklarından koloni faaliyetlerinde ( koloni temizliği, yavru yetiştirme, koloniyi savunma, nektar ve polen kaynaklarından yararlanma) zayıflara oranla daha randımanlıdır. Güçsüz koloniler kendilerini savunamadıkları gibi hastalık ve zararlılarla yeter mücadelede yapamamaktadırlar. Bu nedenle arılıkta zayıf koloni bulundurulmamalı, varsa bunlar birleştirilerek güçlü hale getirilmelidir.

2-Arılarda sonbahar bakımına özen gösterilmeli her kolonide genç ve sağlıklı bir ana arı ile yeterince iş̧̧i arı, bal ve polen bulunması sağlanmalıdır. Besin yetersizliği durumunda koloniler aç kalacağından şurupla besleme yapılmalıdır. Beslemede ballar kullanılmamalı, eğer kullanılacak ise 80 derecede ısıtılmalıdır.

3-illkbahar bakımına da dikkat edilmelidir. Hastalık genelde kış aylarda yayılmakla beraber ölümlerde yoğun olarak ilkbahar aylarında görülmektedir. Yine bu aylarda kolonide azalan veya tükenme durumuna gelen besin maddesine dikkat edilmeli, ihtiyaç var ise zaman geçirmeden besleme yapılmalıdır.

4-Arıların kolonilerini şaşırmaması için önlemler alınmalıdır. Bu amaçla kovanlar tek sıra yerine değişik şekillerde sıralanmalı ve uçuş deliklerinin üzerlerine değişik renk ve şekiller yapılarak boyanmalı, arılar arası ve sıralar arası mesafeler yeterli olmalıdır. Arılıkta yer sorunu yok ise kovanlar arası mesafe 2 metre sıralar arası 4 metre yer sorunu var ise en az 1 metre sıralar arası 2metre kuralına dikkat edilerek hastalıkların yayılmasının önüne geçilmelidir.

5-Arılıkta yağmacılığa dikkat edilmelidir. Bu nedenle kolonilerin ilkbaharda eşitlenmesi sağlanmalıdır. Güç bakımından birbirine eşit olan kolonilerin gelişmesi ve nektardan faydalanması da eşit olacak yağmacılık olayları en aza inecektir. Yine bu amaçla da şaşırmada olduğu gibi giriş deliklerinin farklı yönlere bakmalı, kovanların değişik renklerde boyanmalıdır. Sonbahar ve ilkbaharda uçuş delikleri kontrollü olarak daraltılıp genişletilmesi de koloninin savunmasını arttıracağından önemlidir.

6-Gerekmedikçe ilaç özellikle antibiyotik kullanımından kaçınılmalıdır. Birçok mikroorganizma arıların sindirim sisteminde doğal olarak bulunmakta ve herhangi bir hastalık belirtisine sebep olmadan arı ile birlikte yaşamlarına devam etmektedirler. Kullanılan antibiyotikler arının sindirim sistemindeki doğal florayı bozmakta, bozulan flora bağışlılığı düşürüp hastalıklara ortam hazırlamaktadır.

7-i̇şletmeye koloni temininde mutlaka Varroa zararlısının kontrolü yapılmalıdır. Varroa ile bulaşık koloniler işletmeye alınmamalıdır. Takviye verilirken dikkatli olunmalı hastalığından emin olunmadıkça mevcut kovandan bir başka kovana yavru çerçeve verilmelidir. Keza kaynağı belli olmayan oğullarda arılığa sokulmamalıdır.

8-Kalıntı bırakmaması için arıcıların belalısı olan Varroa zararlısına karşı ilaçlama genellikle son bahar aylarında arı popülâsyonunun az olduğu dönemde yapılmalıdır. Kullanılacak ilaçlar lisanslı olmalı prospektüsünde yazan dozda ve sürelerde kullanılmalıdır.

9- Varroa zararlısı kuluçka alanı olarak erkek arı larvalarının bulunduğu gözleri tercih ettiğinde erkek arı gözlerinin imhası ile bu zararlının önüne geçmek büyük oranda mümkündür.

10-Varroa ya karşı arı sayısının an az olduğu erken ilkbaharda ve geç sonbaharda mutlaka mücadele yapılmalıdır. Kullanılan kimyasallara karşı parazit zamanla direnç kazandığından her yıl aktif maddesi benzer olmayan kimyasalların kullanımına özen gösterilmelidir.

Çıkar Çatışması Beyanı: Makale yazarları aralarında herhangi bir çıkar çatışması olmadığını beyan ederler.

Araştırmacıların Katkı Oranı Beyan Özeti: Yazarlar makaleye eşit oranda katkı sağlamış olduklarını beyan ederler.

\section{Kaynaklar}

Bacandritsos N, Granato A, Budge G, Papanastasiou Roinioti E, Caldon M, Falcaro C, Gallina A, Mutinelli F. 2010. Sudden deaths and colony population decline in Grek honey bee colonies. Journal of Invertebral

Pathology, Doi:10.1016/j.jip.2010.08.004.

Bakoğlu A. Kutlu M A, Kökten K. 2013.Bingöl Yöresinde Bal Arısı (Apis mellifera L.) İçin Önemli Olan Bitkilerin Tespiti, Ömür Uzunlukları ve Çiçeklenme Tarihleri. Tarla Bitkileri Kongresi, Konya,10-12 Eylül KonyaTürkiye

Bakonyi T, Grabensteiner E, Kolodziejek J, Rusvai M, Topolska G, Ritter W, Nowotny N. 2002. Phylogenetic analysis of acute bee paralysis virus strains. Appl Environ Microbiol, 68: 16446-16450.

Bingöl M, Erkan C. 2014. Van İli Arı Hastalıkları ve Zararlılarının Belirlenmesine Yönelik Bir 
Araştırma Yüzüncü Yıl Üniversitesi Tarım Bilimleri Derg. 5(2):14-20

Biesmeijer J. C, Roberts S. P, Reemer $M$, Ohlemüller R, Edwards M, Peeters T, Settele J. 2006. Parallel declines in pollinators and insect-pollinated plants in Britain and the Netherlands. Science, 313(5785), 351-354

Çakmak i, Çakmak. S.S. 2016. Uludağ Arıcılık Dergisi Mayıs 2016, 16 (1): 31-48 / Uludag Bee Journal May 2016, 16 (1): 31-48

Fıratlı Ç, Genç F, Karacaoğlu M, Gençer H.V. 2000.Türkiye'de Arıcılığın Karşılaştırmalı Analizi, Sorunlar-Öneriler. Türkiye Ziraat Mühendisliği V. Teknik Kongresi. 17-21 Ocak 2000. Ankara-Türkiye

Fletcher, M., Barnett, L. 2003. Bee pesticide poisoning incidents in the United Kingdom. Bullet of Insectology, 56: 141-145.352

Garibaldi L. A, Steffan-Dewenter I, Winfree R, Aizen M. A, Bommarco R. 2013. Wild Pollinators Enhance Fruit Set of Crops Regardless of Honey Bee Abundance. Science 339(6127): 1608-1611

Genç F, Dodoloğlu A, 2011.Arıcılığın Temel Esasları. Atatürk Üniv. Ziraat Fak. Ders Yayınları No:341, 207-299 s, Erzurum

Giray T, Cakmak I, Aydin L, Kandemir I, İnci A, Oskay D, Doke M.A, Kence M, Kence A. 2007. Preliminary survey results on 20062007 colony losses in Turkey, Uludag Bee Journal, 7;101-107.

Grixti J. C, Wong L. T, Cameron S. A, Favret C. 2009. Decline of bumble bees (Bombus) in the North American Midwest. Biological Conservation 142, 75-84

Karahan A, Karaca, i.2016.Adana ve Konya illerindeki Arıcılık Faaliyetleri ve Koloni Kayıpları. Süleyman Demirel Üniversitesi Fen Bilimleri Enstitüsü Dergisi Cilt 20, Sayı 2, 226-235, 2016

Karakaya, E., Kızıloğlu, S. 2015. Bingöl îli Bal Üretimi. Iğdır Univ. J. Inst. Sci. \& Tech, 5(2), 25-31.

Köseoğlu $M$, Yücel $B$, Saner $G$, Doğaroğlu $M$. 2008.Türkiye Arıcılığının Güncel Durum Analizi. Hasat Hayvancılık Dergisi, Sayı: 281,52-61.

Kumova U. 2000. Ülke Arıcılığını Çağdaşlaştırma Konusunda Öneriler. Teknik Arıcılık derg. 70,5-10

Kutlu M.A. 1998.Arıcılık Yerinin Seçimi ve Düzenlenmesi. Teknik Arıcılık. 60: 24-25,8

Kutlu M.A, GÜL A. 2015.Bingöl ilinde arıcılık faaliyetleri üzerine bir kesit çalışması. 3.Uluslararası Bölgesel Kalkınma Konferansı 15-16 Ekim 2015 Bingö-Türkiye
Özbek H. 2010. Arılar ve İnsektisitlerin Arılara Olumsuz Etkileri. Uludağ Arıcılık Dergisi: 10 (3): 85-95

Potts S.G, Biesmeijer J.C, Kremen C, Neumann P, Schweiger O, Kunin W.E. 2010. Global pollinator declines: trends, impacts and drivers. Trends Ecol Evol. 2010;25: 345-353.

Rortais A, Arnold G, Halm M.P, Touffet-Briens F. 2005. Modes of honeybees exposure to systemic insecticides: Estimated amounts of contaminated polen and nectar consumed by different categories of bees. Apidologie, 36: 71-83

Sandrock C, Tanadini M, Tanadini L.G, FauserMisslin A, Potts, S.G, Neumann P. 2014. Impact of chronic neonicotinoid exposure on honeybee colony performance and queen supersedure. PLOS ONE. 2014:9: e103592.

Sever R, Koca H. 2008 Beekeeping Potential in Karlıova and Use Of This Potential Doğu Coğrafya Dergisi, acikerisim.giresun.edu.tr

Sıralı R, Doğaroğlu M. 2005.Trakya Bölgesi Arı Hastalıkları ve Zararlıları Üzerine Anket Sonuçları. Uludağ Arıcılık Dergi. 5: 71-78.

Söğüt, B., Şeviş, H.E., Karakaya, E., İnci, H., Yılmaz, H.Ş. 2019a. Bingöl îlinde arıcılık faaliyetinin mevcut yapısı üzerine bir araştırma. Türk Tarım ve Doğa Bilimleri Dergisi, 6(2): 168177.

Söğüt, B., Şeviş, H.E., Karakaya, E., İnci, H. 2019 b. Arıcılık İşletmelerinde mevcut durum temel sorunlar ve çözüm önerileri üzerine bir araştırma (Bingöl ili örneği). Uludağ Arıcılık Dergisi, 19(1): 50-60.

TÜik. 2018 verileri. (www.tüik.gov.tr)(erişim tarihi:20.01.2020)

Tüzün A, Bilgili G. 2013.Tarımsal Ekosistemde Arıların Önemi. Biyoloji Bilimleri Araştırma Dergisi 6 (2): 91-95

Ünal H.H. 2010. Research of honey bee colony losses and deaths in Marmara region. 4th EurBee Congress Book, p. 64, 7-9th September 2010, Ankara, Turkey.

VanEngelsdorp D, Hayes J.Jr, Underwood R.M, Pettis J. 2008. A survey of honey bee colony losses in the U.S. Fall 2007 to Spring 2008. PLOS ONE, 3(12):e4071.

Whitehorn P. R, Conno S, Wackers F. L, Goulson D. 2012. Neonicotinoid pesticide reduces bumble bee colony growth and queen production. Science 336, 351

Yılmaz F.2009.Koloni Çöküş Hastalığı Ordu arıcılık araştırma enstitüsü dergisi Yıl 1 Sayı

Yue C, Schroder M, Gisder S, Genersch E, 2007. Verticaltransmission routes for deformed 
wing virus of honeybees (Apis mellifera). J Gen Virol, 88: 2329-2336

Yücel B. 2008.Çevresel Sorunların Bal Arıları Üzerine Etkileri. Hasad.279: 40-43. 